\title{
A Aprendizagem Ativa Na Formação De Uma Liderança Participativa E Democrática Nas Empresas
}

\section{Active Learning In The Formation Of A Participatory And Democratic Leadership In Business}

Alessandro Rossini ${ }^{1}$, Fernando José Lopes²

\begin{abstract}
1. Alessandro Rossini. Prof, Pós Doc. em Administração, Doutor em Comunicação e Semiótica, Mestre em Administração. Organização/Planejamento Estratégico/PUC-SP, Pós-graduação em Administração, Graduado em Física e Processos Gerenciais. Graduação e Pós, Administração, Educação e Comunicação/TI CV lattes: http://lattes.cnpq.br/5109240355917713. E-mail: alessandro.rossini@yahoo.com

2. Fernando José Lopes, é Mestre em Cognição e Semiótica PUC-SP, pós-graduado em Gestão de Pessoas. Graduado em Administração pela FICS. Professor dos cursos de gestão, graduação e pós-graduação na FICS Campos Salles, Faculdade Flamingo nos cursos de gestão e pós-graduação na Universidade Paulista (UNIP). lopesfj2008@gmail.com.
\end{abstract}

\section{Resumo}

A aprendizagem ativa na formação de uma liderança participativa e democrática nas empresas visa demonstrar uma proposta de trabalho com foco em uma liderança mais eficiente e eficaz a partir da aprendizagem ativa. A ideia é que as equipes de alta performance trabalhem com enfoques relacionados a modelos de liderança cognitivos e transacionais, utilizando a aprendizagem ativa como referência para desenvolver liderança participativa e democrática nas empresas. A proposta metodológica está baseada em um estudo exploratório com base descritiva acerca do referencial teórico que sustenta a investigação. Por meio da troca de informações entre os indivíduos de uma equipe se busca a liderança equilibrada, que motiva os colaboradores e, ao mesmo tempo, estimula a colaboração na produtividade a partir do conhecimento das novas formas de liderança organizacional.

Palavras-chave: liderança participativa; aprendizagem ativa; transacional

\begin{abstract}
Active learning in building a participatory and democratic leadership in business aims to demonstrate a work proposal focused on a more efficient and effective leadership from the active learning. The idea is that high performance teams to work with approaches related to cognitive and transactional leadership models using active learning as a reference to develop participatory and democratic leadership in business. The methodology is based on an exploratory study with descriptive based on the theoretical framework that supports the research. Through the exchange of information between individuals of a team seeking a balanced leadership that motivates employees and at the same time, encourages collaboration productivity from knowledge of new forms of organizational leadership.
\end{abstract}

Keywords: participatory leadership; active learning; transactional 


\section{Introdução}

A pesquisa visa discutir questões relacionadas à melhoria no processo de liderança utilizando a aprendizagem ativa como uma das maneiras para alavancar melhores resultados nos processos produtivos nas empresas. A aprendizagem ativa, baseada na troca de informações, pode auxiliar, de forma significativa, para a construção cognitiva de valores e conhecimentos em um processo participativo e colaborativo, de maneira a valorizar a vivência e as informações necessárias para alavancar novas formas de trabalho entre líderes e liderados em uma empresa.

A ideia principal defendida neste artigo é trabalhar com a informação e a troca de experiências em um contexto corporativo, objetivando a liderança participativa e colaborativa por meio da utilização da aprendizagem ativa, ou seja, pressupõe uma construção da liderança com a contribuição do liderado e de suas experiências e com a mediação do líder na construção de novos conhecimentos referentes a essa atividade.

O mais importante a ser considerado é a possibilidade do respeito do líder pelos seus liderados a ponto de dar espaço para que todos cooperem para produção de resultados em equipe, de forma a valorizar o papel de cada um no processo da construção de uma liderança, assim como seu significado nas ações e resultados obtidos pela equipe.

Para o líder, a experiência de descentralizar suas tarefas valorizando seu colaborador como pessoa capaz de criar e participar das propostas de trabalho dentro de uma equipe é bastante profícuo. Para o colaborador, a oportunidade de não apenas fazer parte do processo, mas criá-lo de maneira compartilhada e participativa, com suas ideias, ações, experiência de vida, capital intelectual, em uma proposta de trabalho mais justa, dinâmica e com resultados mais significativos para a equipe é igualmente muito importante. A troca de informações gera conhecimento, que será utilizado nas ações propostas no projeto e que, por meio da rede social, será controlada por todos, consultada e passada pelo móbile em tempo real para cada indivíduo não ter problemas nas suas atividades rotineiras em equipe.

O objetivo geral desse estudo é o de demonstrar que, por meio da aprendizagem ativa, os indivíduos participantes de um determinado processo de liderança podem construir, com seu líder, com uma forma de trabalho mais eficiente e eficaz ao intercambiar informações e construir maneiras mais positivas de trabalho em equipe, valorizando uma liderança mais participativa na produção de melhorias contínuas no processo de liderança. $\mathrm{O}$ objetivo específico dessa abordagem, discute os diversos conhecimentos dos liderados de 
maneira a contribuir para a melhoria do modelo de liderança, bem como para a equipe como um todo.

A problemática está em quanto este método pode auxiliar na concepção de equipes com liderança colaborativa e participativa ao oferecer melhores resultados a equipes que trabalham utilizando a aprendizagem ativa como concepção de uma liderança baseada na construção de conhecimentos.

A justificativa para a escolha do tema é o de uma equipe focada na colaboração e participação dos indivíduos em todo processo cognitivo e construção do novo modelo de liderança, fazendo com que estes indivíduos sintam como parte formadora do processo de liderança e forma de trabalho em uma equipe colaborando para resultados de alta performance no trabalho.

A proposta metodológica discutida está baseada em pesquisa bibliográfica e eletrônica, estudo exploratório com base descritiva acerca do referencial teórico pesquisado. Há muitas razões para se realizar uma pesquisa. Nesta, identifica-se classifica conceitos de acordo com os conceitos teóricos de Gil (2010, p.1), dois grandes grupos: de ordem intelectual e de ordem prática. A pesquisa bibliográfica, como qualquer outra, desenvolve ao longo de etapas, definição da natureza do problema, nível de conhecimento e informação sobre o assunto que pesquisador propõe pretende conferir, como segue: $\mathrm{O}$ gerente de projetos de Rabechini Jr (2009). Alegretti, (2003). Becker, (2009). De
Berbel, (2009) As Metodologias Ativas. Com Bergamini, (2009) O líder eficaz. De Bordenave, (2005) A estratégia de ensino. Com Castilho (2011) EAD: Interatividade e método. Lopes. 2013. De Coll (2004) Desenvolvimento Psicológico e Educação. A Pedagogia da Autonomia de Freire (2003). Lopes (2013) e as Teorias da aprendizagem construtivistas. A competência da liderança de Marinho (2006). A aprendizagem pela ação de Marquardt (2005). O comportamento no gerenciamento de Maslow (2000). As Metodologias ativas de Mitre (2008). Moreira (2009). Os Estilos, estratégias e metacognição de Portilho (2009). Estratégias de Aprendizagem Ativa de Reis (2010).

Procurou-se desenvolver aqui a pesquisa principalmente por meio de livros, artigos científicos, revistas.

\section{1 - Aprendizagem E Sua Importância No Processo Cognitivo $\mathrm{Na}$ Construção De Uma Liderança Em Uma Empresa.}

A aprendizagem está ligada a uma troca de informações entre aluno ou liderado e professor ou líder, motivada por um ponto de desequilíbrio estabelecido entre a proposta de ensino realizada por parte do mediador e o interesse do aluno em buscar respostas. Quando os dois chegam a um acordo, existe o equilíbrio e, portanto, a educação. O mediador conseguiu chegar ao seu propósito. Nessa interação, ao assimilar os conceitos e acomodá-los, o aluno aprendeu, poderá discutir seu ponto de vista 
com o educador e haverá crescimento para ambas as partes (LOPES, 2013).

Em um contexto empresarial, ao se falar em equipes e liderança participativa e democrática, a ideia, assim como no âmbito escolar, é a troca de informações entre os integrantes da equipe, ou seja, líderes e liderados juntos necessitam conseguir promover uma liderança eficiente e eficaz que traga resultados para ambas as partes envolvidas no processo. Para que a educação seja prazerosa e traga assimilação e progresso, o professor ou líder, como mediador, necessita propiciar condições para que o aluno tenha prazer em aprender, que entenda os conceitos, que consiga identificar, no seu meio, o que está sendo ensinado. Mas, para isso, o professor deve estar preparado para ser um mediador.

Em consonância com Castilho observase que:

\footnotetext{
Aprender é muito mais do que receber informações. Envolve percepção, seleção, cognição, organização. Envolve atitude. Envolve sociabilização. São as três dimensões do discurso: sintaxe, semântica e pragmática a forma, o significado e aplicação [...] associada necessariamente à linguagem, sempre regidas pela lógica (CASTILHO, 2011, p.39).
}

Quando falamos de aprendizagem ativa na construção de uma liderança, os elementos envolvidos são o assunto a ser abordado, as estratégias ou ações a serem implementadas mediante um planejamento, a execução das ideias, o acompanhamento ou experimentação da proposta e, por fim, a avaliação e validação dos resultados conseguidos pela equipe. Conforme Allegretti (2003, p. 44),

O contexto não é uma realidade única, rígida e acabada, ele permite a expansão da rede a partir da multiplicação das relações, pois o contexto faz, parte da rede social e permite atribuir significados, valores e crenças ao objeto do conbecimento. O que ocorre, entretanto, é que se apresentando como uma rede, ele assume características da não linearidade, objeto de permanentes mutações. Isso faz. com que se atribuam diferentes significados às informacõos inseridas nesse ambiente (ALLEGRETTI (2003, p. 44),

Parte da aprendizagem ativa pode ser trabalhada com os meios virtuais. Uma das propostas é a interatividade dos indivíduos por meio das redes sociais, ou ainda em reuniões em laboratório preparado para que os indivíduos interajam em tempo real pela mídia, trocando informações que podem ser buscadas na rede, ou ainda pela construção de conceitos individuais que irão compor o todo de uma proposta de trabalho. Conforme apontamentos de Coll: [...] o desenvolvimento consiste na construção de uma série de estruturas que determinam a natureza e a amplitude das trocas das pessoas com seu meio e que, além disso, sucedem-se invariavelmente respeitando a tendência a um equilíbrio melhor [...] (COLL, 2004, p.48. Na aprendizagem ativa, o que se trabalha é a construção das estruturas de informações que são filtradas pelos 
participantes e que, por meio das trocas de informações com o grupo, irá gerar o conhecimento participativo e colaborativo entre a equipe a fim de formar uma proposta em consenso em termos de uma liderança eficiente e eficaz para determinado setor.

\section{1 - O Que É Aprendizagem Ativa?}

$\mathrm{Na}$ aprendizagem ativa, o aluno ou liderado é o ser central, ele é o principal construtor do processo de ensino. Nessa modalidade, o professor ou o líder não ensina diretamente, ele cria ferramentas e constrói junto aos alunos um ambiente favorável à aprendizagem. Essas ferramentas são as propostas pedagógicas implícitas no processo ensino-aprendizagem em que o professor ou líder dá condições para que o aluno crie, com seu conhecimento e experiências, novas propostas de trabalho de um conteúdo ou contexto. É importante ressaltar que, quando um aluno ou liderado conhece algo sobre o assunto abordado, torna-se mais fácil a aprendizagem, pois a proposta ou assunto tratado pode já ter algum significado para esses integrantes da equipe e, portanto, torna-se mais fácil trabalhar os conteúdos para a formação de conhecimento.

$$
\text { Conforme Moreira e Masini, a }
$$
aprendizagem significativa propõe que:

a) O material a ser aprendido seja potencialmente significativo para o aprendiz, ou seja, relacionável a sua estrutura de conhecimento de forma não arbitrária e não literal (substantiva).

b) $\mathrm{O}$ aprendiz manifeste uma disposição de relacionar o novo material de maneira substantiva e não arbitrária a sua estrutura cognitiva. MOREIRA E MASINI (2009, p.62).

Quanto mais informação o aluno tem para estudar e apreender, mais ele vai usar estratégias de aprendizagem ativa, isto é, estratégias criativas, que tenham significado para o aluno e que o ajudem a decidir como e o que vai integrar. O papel do mediador é proporcionar condições para que o aluno ou liderado busque informações para construir seu raciocínio dentro do assunto abordado e consiga fazer relações com o que já conhece para estabelecer uma nova linha de raciocínio e construção de novos conhecimentos ou formas de trabalho. Diferentemente da aprendizagem passiva, a ativa não possui técnicas, mas estratégias. Na concepção de Portilho:

Os dois termos são comumente classificados como sinônimos, mas na realidade tem significados distintos. Estratégia é um termo militar utilizado para denominar a arte de dirigir operações na condução de conflitos baseado em um conjunto de regras que asseguram uma decisão adequada a cada momento. Por outro lado a técnica é o conjunto de processos de uma arte ou ainda maneira, jeito ou habilidade especial de executar uma determinada tarefa. Pode-se concluir que numa estratégia os individuos envolvidos devem compreender o que e o porquê estão fazendo tal atividade (PORTILHO, 2009, p.48). 
$\mathrm{Na}$ proposta de aprendizagem ativa, a ideia não é passar o conhecimento pronto e acabado como paradigma de realidade comum a todos, mas estabelecer um elo entre o que já se conhece e o que pode ser melhorado ou ainda agregado ao que já existe, fazendo com que o aluno ou colaborador construa junto com o professor ou líder novas propostas de conhecimento sobre o assunto trabalhado. Um dos proponentes deste modelo foi Paulo Freire (1996), que desencorajava o modelo "bancário" de educação, no qual os docentes depositavam conhecimento nas mentes dos estudantes, da mesma forma que depositamos dinheiro numa conta corrente, para que os estudantes possam gastá-lo na hora das provas. A aprendizagem ou liderança em um aspecto ativo não é algo acabado, mas é uma perspectiva de mudanças contínuas que contribuem para o crescimento do liderado ou do aluno ao construir novos significados para os seus saberes e conhecimentos, sendo, portanto, um processo contínuo e evolutivo. Conforme Becker:

\footnotetext{
"A assimilação funciona como um desafio sobre a acomodação a qual faz originar novas formas de organização. Resumindo, a assimilação sob o ponto de vista psicológico é um fato primordial, pois, em todos os dominios, ela se apresenta como a origem e o resultado da organização” Becker (2009, p.35),.
}

A tecnologia pode desempenhar importante papel no ensino, garantindo que a aprendizagem seja o resultado do diálogo e da produção de novos conhecimentos por meio das novas mídias, tornando o conteúdo mais interessante e relevante. Quando um aluno apenas ouve a aula do professor e depois lê o livro didático em casa, ele não desenvolve todo seu potencial de aprendizagem (REIS, 2010). De acordo com pesquisa publicada no Manual do Facilitador, Freire (2003 apud LASSER, 2002, p.56) assinala que o aluno retém:

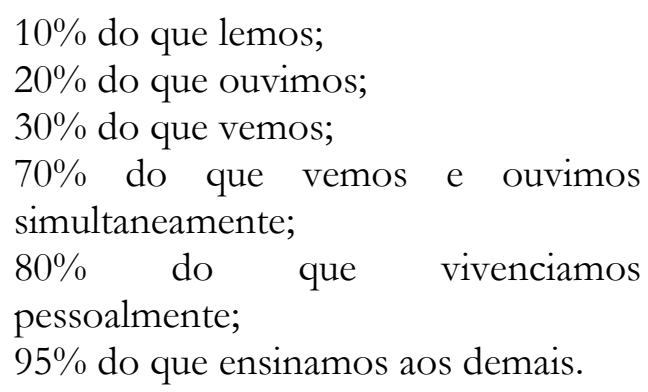

Logo, a interação com o meio a ser estudado, as estruturas cognitivas desenvolvidas pela experimentação, a troca de ideias e informações filtradas, são fundamentais para construção de um conhecimento sobre o assunto abordado, seja em um processo de liderança na escola ou na empresa. As metodologias ativas têm o potencial de despertar a curiosidade, à medida que os alunos se inserem na teorização e trazem elementos novos, ainda não considerados nas aulas ou na própria perspectiva do professor (BERBEL, 2011). Bastos (2006) e Berbel (2011) definem uma conceituação de Metodologias Ativas como processos interativos de conhecimento, análise, estudos, pesquisas e decisões individuais ou coletivas, com a finalidade de encontrar soluções para um problema. 
1.2 - Modelos De Aprendizagem Ativa

\subsection{1 - Aprendizagem exploratória}

O modelo de aprendizagem exploratória ocorre quando temos referências baseadas no que os outros já escreveram ou publicaram em livros, vídeos, sites, enfim envolve todo tipo de informação disponível e que tenha real significância para o processo de elaboração de um modelo para construção do conhecimento, seja em termos acadêmicos ou corporativos. Serve como um arquivo onde buscamos informações pertinentes e significativas para construção de um conhecimento que será utilizado no processo de aprendizagem, tanto na liderança cognitiva participativa de uma equipe, quanto para a educação acadêmica. Essa metodologia de aprendizagem pode ser usada quando estamos buscando uma resposta para as nossas dúvidas referentes a uma determinada situação ou ainda sobre conteúdos que iremos abordar em uma proposta de trabalho ou em um contexto acadêmico que envolva novos saberes.

No caso da produção de um artigo científico, em que reelaboramos conceitos e os ampliamos para explicar assuntos relacionados a um tema, ou então quando abordamos ou nos aprofundamos em determinado assunto de uma temática informativa, seja em um contexto acadêmico ou corporativo, o uso dessa proposta de aprendizagem é bastante rico. Igualmente pode ser utilizada quando questionamos assuntos ou modelos a respeito de algum assunto já elaborado e publicado por outras pessoas, mas que podemos aperfeiçoar ou ainda quando não concordamos com a proposta feita pelo autor.

$$
\begin{aligned}
& \text { Essa metodologia pode contribuir, de forma } \\
& \text { significativa, para tratar sobre um assunto já } \\
& \text { abordado por outra pessoa no meio acadêmico } \\
& \text { ou na empresa se queremos ampliar o } \\
& \text { significado do conhecimento por termos } \\
& \text { referências diferenciadas sobre o assunto } \\
& \text { abordado escrito (PORTILHO, 2009, p.45). }
\end{aligned}
$$

\subsection{2 - Aprendizagem colaborativa}

Ocorre a aprendizagem colaborativa quando existe uma troca de informações simultâneas que colaboram para a formação do conhecimento entre os participantes envolvidos no processo. Nesta modalidade, a aprendizagem se dá pela troca de ideias e informações, pela discussão, pela crítica recíproca, pelo reforço emocional mútuo; enfim, pela colaboração e pelo diálogo. É preciso ressaltar que as duas modalidades de aprendizagem ativa envolvem comunhão noção para a qual Paulo Freire chama a nossa atenção - e que, portanto, nenhuma delas, nem mesmo a primeira, que também é chamada de autoaprendizagem, deve ser caracterizada como uma aprendizagem em isolamento do outro, uma aprendizagem solitária, no sentido literal (REIS, 2010).

\subsection{3 - Ensino pela problematização}

O ensino pela problematização ou ensino baseado na investigação (Inquiry Based Learning )surgiu nos Estados Unidos, no estado do Havaí, 
na década de 80 , com o objetivo de dar espaço para que os estudantes não apenas participassem do processo educacional, mas que construíssem sua educação, algo importante e significativo quando falamos de equipes, líderes e liderados, utilizando a aprendizagem ativa (MITRE et al, 2008). Essa concepção pedagógica baseia-se no aumento da capacidade do discente em participar como agente de transformação social, durante o processo de detecção de problemas reais e de busca por soluções originais. Marcada pela dimensão política da educação e da sociedade, o ensino pela problematização procura mobilizar o potencial social, político e ético do estudante, para que este atue como cidadão e profissional em formação.

Bordenave e Pereira (2005) trabalham com uma metodologia baseada no gráfico do arco desenvolvida por Charles Maguerez, que procura utilizar uma sequência de fatores para justificar a aprendizagem significativa e ativa em um processo de construção do conhecimento.

Figura 1: Arco de Maguerez

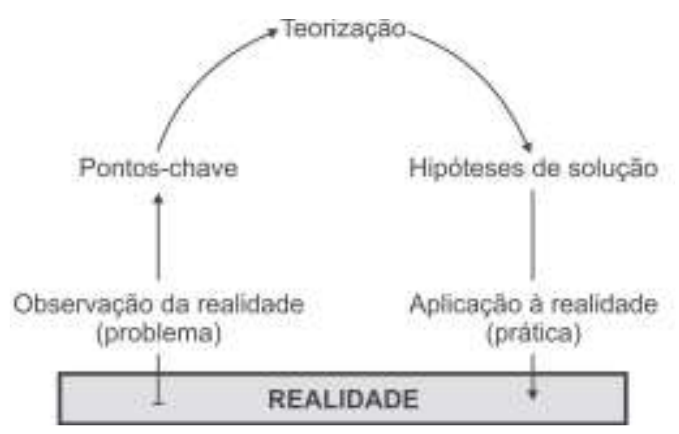

Fonte: BORDENAVE, J.; PEREIRA, A. A estratégia de ensino aprendizagem. 26. ed. Petrópolis: Vozes, 2005.
A primeira fase trabalha com o aspecto da realidade, ou seja, o material disponível como informação para servir como suporte às problemáticas futuras a serem estudadas para uma melhor estruturação cognitiva. A partir da informação inicial, o aluno ou liderado analisará o que é mais relevante dentro do assunto e extrairá os pontos fundamentais para montar um projeto favorável à sua aprendizagem e aplicabilidade dentro de uma proposta de projeto. $\mathrm{Na}$ terceira fase, o aluno ou liderado procurará estabelecer a lógica do que ele pretende trabalhar em loco na empresa ou na escola e fazer ligações com o que sabe e o que poderá ser acrescentado a seu aprendizado. $\mathrm{Na}$ quarta fase, busca estabelecer novas formas de melhoria no conhecimento do indivíduo, alcançando novas fronteiras e maneiras de trabalhar determinado assunto, seja em um contexto acadêmico, ou empresarial.

$\mathrm{Na}$ última fase, o aluno ou liderado será capaz de experimentar seu novo conhecimento aplicando-o às necessidades como indivíduo participante em um processo de aprendizado, tanto na escola, como em seu trabalho.

\section{2 - A Aprendizagem Para Compor Uma Equipe Adequada}

A aprendizagem é caracterizada por assimilação do conteúdo, que nada mais é que uma internalização transformada em conhecimento. Esse conhecimento será aplicado ou praticado pelo indivíduo e agregará nova 
informação àquela que já foi aprendida e será acomodada, dando origem a um novo processo. Dessa maneira, a aprendizagem pode ser contínua, desde que haja interesse por parte do indivíduo e que essas novas informações façam significado com o que ele já aprendeu, é um processo constante. Conforme Dilworth (apud MARQUARDT, 2005, p.118), o aprendizado decorrente de um programa de aprendizagem pela ação tem maior valor estratégico para a organização do que a vantagem tática imediata de resolver um problema.

A aprendizagem em uma equipe depende muito das relações existentes entre os indivíduos, depende da confiança que um tem no outro, assim como da forma que a informação é passada entre os indivíduos. A confiança e a maneira de experimentar as formas de se conseguir resultados na prática propicia uma maneira de aprender, experimentar e agregar valor ao que se já sabe.

De acordo com Marquardt (2005, p.119),

O grau e a qualidade da aprendizagem não são
inesperados, porque se desenvolvem por meio de
pessoas reais que trabalham umas com outras
emproblemas reais, buscando um conbecimento
que provocará uma mudança positiva
(MARQUARDT, 2005, p.119).

A aprendizagem se dá nessas equipes de forma colaborativa e participativa. Cada um está preocupado com o resultado e, para que isso ocorra, cada fase e cada indivíduo deve buscar a melhor maneira de executar suas tarefas. A participação dos outros pares se torna importante à medida que podem contribuir de forma significativa com informações compartilhadas na equipe. $O$ processo de aprendizagem nessas equipes é de responsabilidade de todos, portanto é importante que cada um tenha interesse em aprender para si, mas também para colaborar com o trabalho feito para a equipe, pois isso facilitará o desenrolar das ações para busca dos resultados desejados por todos. A liderança, nesse aspecto, fica por conta de toda a equipe e cada um olha pelo outro e colabora para que os indivíduos se esforcem para aprender não apenas seu trabalho, mas o projeto como um todo, de modo que cada um poderá ajudar seu parceiro de trabalho em um momento de dificuldade na equipe.

O mediador precisa ter consciência de que deve propiciar condições para a aprendizagem, de preferência em situações práticas nas quais o indivíduo possa interagir com o ambiente. No caso do mobile learning, a liderança participativa e colaborativa deve existir com reflexões e críticas construtivas e também de autocríticas para que os indivíduos possam se avaliar de forma constante, sobretudo no que se refere a seu desempenho dentro do projeto.

Aprender é um ato contínuo e está presente em todo o processo de aprendizagem pela ação. As oportunidades para questionar, refletir e aprender surgem a todo momento. (MARQUARDT, 2005, p.121). 
2.1 - Abordagens De Uma Liderança Cognitiva

A liderança cognitiva aborda a percepção dos colaboradores em relação à liderança. Os indivíduos da equipe julgam a liderança pelas interações e forma de comando do líder dentro de uma perspectiva de conseguir resultados adequados dentro do projeto. A questão em si está na cultura dos participantes, ou seja, dos liderados. A cultura pode ser moldada de acordo com a confiança depositada do líder com a participação da equipe e colaboração em prol das ações para conseguir melhores patamares de produtividade, economia de tempo e flexibilidade das informações, uma linguagem com que todos cooperam para um resultado em comum. De acordo com Marinho e Oliveira (2006, p. 13), "a teoria pressupõe que a avaliação do comportamento do líder depende mais da cultura dos seguidores que do comportamento do líder propriamente dito".

\section{2 - Liderança Tranformacional}

Neste modelo de liderança, o foco está nas ações e conhecimentos dos indivíduos e o que eles podem trazer como melhorias na liderança em determinada equipe. Em equipes de alta performance, os indivíduos têm participação significativa na concepção e idealização dos processos de trabalho; logo, não apenas participam do processo, mas colaboram para que o processo seja estruturado com base em seus conhecimentos, seja em termos de vivência corporativa ou de ordem acadêmica. De acordo com Bergamini (2008, p.143 apud MASLOW, 2000, p.189): “as exigências de diferentes tipos de situações em que há diferentes líderes variam bastante". Esse é um fato relevante e significativo que deve ser observado nas empresas, pois existem pessoas com cognição diferenciada sobre liderança, bem como modelos de líderes diferenciados. Logo, a aplicabilidade de uma liderança transformacional vai depender muito dos elementos que colaboram para o desenvolvimento dessa liderança, mesmo que ela seja baseada em uma aprendizagem ativa. Conforme Rabechini Jr. (2011, p.201 apud MASLOW, 2000);

\footnotetext{
A liderança transformacional apresenta-se como instrumento para ativar as necessidades de alto nivel de Maslow. Ela enfatiza a mudança (ou transformação) em um processo. Talvez um dos aspectos menos explorados pelos gerentes de projetos seja justamente este: a utilização da liderança como instrumento para influenciar sua equipe (RABECHINI Jr., p.201).
}

Dentro de uma perspectiva transformacional em que o líder dá espaço para os indivíduos se moldarem à nova proposta de trabalho muitas vezes por meio de sua contribuição, chegamos ao ponto crucial do estudo em uma equipe de alta performance pode ser construída através da aprendizagem ativa. 
3 - A Aprendizagem Ativa Na Formação De Uma Liderança Participativa E Democrática Nas Empresas

A aprendizagem ativa baseia-se na troca de informações por parte dos alunos ou liderados em prol da busca de novos conhecimentos, partindo de informações que são tratadas e discutidas pelos participantes do processo na busca de novos patamares de conhecimento. De acordo com Bergamini (2008, p.148), "a liderança transacional ocorre quando uma pessoa toma a iniciativa de estabelecer contato com outras com o objetivo de trocar bens de valor". Uma proposta ativa na formação da liderança participativa e democrática na empresa, estamos nos referindo exatamente a esses intercâmbios entre líderes e liderados em que a participação dos liderados possa contribuir para uma liderança mais eficiente e eficaz por meio das trocas estabelecidas entre as partes envolvidas no processo de construção do conhecimento, visando a uma liderança mais adequada a todos.

\section{1 - O Projeto}

\subsection{1 - Diagnóstico}

Problemas relacionados à liderança e interação dos indivíduos com seu líder. Neste caso, a aprendizagem ativa quebra a barreira em relação ao relacionamento líder e liderado, pois dá possibilidades da interação entre as partes e existe um cooperativismo entre elas para busca de soluções para o trabalho em equipe. A ação é dos grandes problemas nas equipes entre líderes e liderados é a aceitação das ideias por parte dos indivíduos. Existem conflitos relacionados ao ego de quem lidera e descontentamento por parte dos liderados por suas ideias muitas vezes não serem aceitas pelos líderes. No que se refere à aprendizagem ativa, todos colaboram para um só projeto, no qual ambas as partes, líder e liderados, trabalham em equipe com seus conhecimentos para formularem uma liderança mais participativa e colaborativa justa, de forma que ambas as partes saiam satisfeitas com o resultado, até porque todos colaboraram com o processo de criação do modelo de liderança utilizando sua cognição individual, que propiciou resultados coletivos.

A implementação é pensada a partir de uma ideia central - se existe uma troca de informações que sejam filtradas e mediadas pelo líder, buscando satisfazer as necessidades de toda equipe em termos de aprendizado, de construção de conhecimento e de um modelo de liderança que agrade a todos os envolvidos no processo, aí existe a possibilidade se se implantar um processo.

O acompanhamento nesta fase, é importante que todas as informações passadas pelos envolvidos no processo, tanto liderados como líderes, sejam filtradas de forma a construírem um novo processo de liderança que garanta o sucesso da equipe em termos de resultados para empresa, assim como satisfaça as 
necessidades dos indivíduos da equipe como colaboradores.

$\mathrm{Na}$ avaliação e validação é importante ressaltar que o projeto só dará certo se todos os envolvidos colaborarem para a construção e estiverem de acordo com o modelo final elaborado com base no conhecimento coletivo. Dessa forma, a avaliação será feita por todos os envolvidos no projeto e validada pelo líder e pelos liderados.

O Feedbacké a parte mais importante do processo e trata do retorno do projeto colocado em prática. O processo de retorno aos participantes será dado durante o tempo de exercício da nova proposta de trabalho utilizando a aprendizagem ativa como elo entre conhecimento e construção de novas formas de liderança participativa e colaborativa na empresa, um processo contínuo que pode ser melhorado de forma constante, basta utilizar os conhecimentos dos pares envolvidos em novas formas de trabalho.

\section{4 - Considerações Finais}

Podemos observar que, por meio da aprendizagem ativa, a interação dos liderados no projeto de liderança participativa e colaborativa assume um papel de responsabilidade por parte do liderado, pois ele passa de sujeito, antes passivo, executando ordens sem questionamentos, para ativo e, agora, com essa proposta, ele ajuda a criar formas de trabalho relacionadas à liderança e ele não só executa, mas cria novas possibilidades de relacionamento entre líder e liderado. Além do espaço que é dado ao colaborador em termos de participação no processo de criar um novo modelo de liderança, este indivíduo irá se sentir útil no processo de construção, pois sua parte cognitiva dará contribuição significativa para que o processo utilizado pela equipe funcione.

Cabe ressaltar que a ideia do projeto pode funcionar desde que haja comprometimento das partes envolvidas no processo, de um lado a mediação do líder em ser capaz de entender as ideias dadas pelo liderado e administrar resultados que sejam significativos a todos envolvidos; de outro lado, o comprometimento da equipe de forma a contribuir significativamente para a construção desse novo modelo de liderança na empresa. A ideia é que, por meio da aprendizagem ativa, os indivíduos liderados sintam poder colaborar e participar para a construção de um modelo de liderança em que o líder respeite as necessidades e expectativas dos liderados, mas que, ao mesmo tempo, os liderados colaborem para que a equipe seja altamente produtiva e tenha um desempenho melhor que os anteriores no processo produtivo na empresa.

\section{Referências Bibliográficas E Eletrônicas}

ALEGRETTI, Sonia Maria Macedo.

Diversificando os ambientes de aprendizagem na formação de professores para o 
desenvolvimento de uma nova cultura. Tese de Doutorado PUC: São Paulo, 2003.

BECKER, Fernando. A epistemologia do professor: o cotidiano da escola. 14.ed Rio de Janeiro:Vozes, 2009.

BERBEL, Neusi Aparecida Navas. As Metodologias Ativas e a Promoção da Autonomia de Estudantes. Semina: Ciências Sociais e Humanas, Londrina, v. 32, n. 1, p. 2540, jan./jun. 2011.

BERGAMINI, C. W. O líder eficaz. São Paulo: Atlas, 2009.

BORDENAVE J, Pereira A. A estratégia de ensino aprendizagem. 26. ed. Petrópolis: Vozes, 2005

CASTILHO, R. Ensino a distância EAD: Interatividade e método. São Paulo: Atlas, 2011.

COLL, Cesar; PALACIOS, Jesús; MARCHESI, Alvaro. Desenvolvimento Psicológico e Educação. Vol. 2. 2.ed. Porto Alegre: Artmed, 2004.

FREIRE, Paulo. Pedagogia da Autonomia. 27. ed. São Paulo: Paz e Terra, 2003.

GIL, Antônio, C. Como elaborar projetos de pesquisa. São Paulo: Atlas, 2010.
LOPES, F. J. Teorias da aprendizagem construtivistas: uma proposta de ensino utilizando ambientes virtuais de ensino aprendizagem para propor uma abordagem construtivista no ensino presencial. Dissertação de Mestrado, PUC, São Paulo, 2013.

MARINHO, R. M.; OLIVEIRA, J. F. (org.). Liderança: uma questão de competência. São Paulo: Saraiva, 2006.

MARQUARDT, M. J. O poder da aprendizagem pela ação: como solucionar problemas e desenvolver líderes em tempo real. Tradução Anna Lobo. Rio de Janeiro: Senac Rio, 2005.

MASLOW, A. H. Maslow no gerenciamento. Rio de Janeiro: Qualitymark, 2000.

MITRE, S. M. (et.al) Metodologias ativas de ensino-aprendizagem na formação profissional em saúde: debates atuais, Ciência \& Saúde Coletiva, 2008.

MOREIRA, Marco Antonio; MASINI, Elcie F. Salzano. Aprendizagem significativa: a teoria de David Ausubel, São Paulo: Centauro, 2009.

PORTILHO, Evelise. Como se Aprende? Estilos, estratégias e metacognição. Rio de Janeiro: WAK Editor, 2009.

RABECHINI JR., R. O gerente de projetos na empresa. 3.ed. São Paulo: Atlas, 2011. 
REIS, L. R. M. (2010). Estratégias de Aprendizagem Ativa para Reduzir o Fracasso Escolar: Papel Psicopedagogo. Brasília. http://proerdpmdf.files.wordpress.com/2010/

07/aprendizagem -ativa1.pdf acessado dia $26 / 06 / 2014$ 